See discussions, stats, and author profiles for this publication at: https://www.researchgate.net/publication/256445054

\title{
Influence of the pressure head sequence on the hydraulic conductivity determined with tension infiltrometer
}

Article in Applied engineering in agriculture · May 2005

DOI: $10.13031 / 2013.18457$

CITATIONS

33

3 authors:

Vincenzo Bagarello

Università degli Studi di Palermo

99 PUBLICATIONS 1,661 CITATIONS

SEE PROFILE

Massimo lovino

Università degli Studi di Palermo

128 PUBLICATIONS 1,373 CITATIONS

SEE PROFILE
READS

169

Mirko Castellini

Council for Agricultural Research and Agricultural Economy Analysis 65 PUBLICATIONS 347 CITATIONS

SEE PROFILE

Some of the authors of this publication are also working on these related projects:

Investigations about soil hydraulic characteristics of the experimental basin View project 


\title{
Influence of the Pressure Head Sequence on the SoIl Hydraulic Conductivity Determined WITH TENSION INFILTROMETER
}

\author{
V. Bagarello, M. Castellini, M. Iovino
}

\begin{abstract}
An increasing and a decreasing sequence of pressure head, $h_{0}$, values were applied with the tension infiltrometer (TI) to determine the corresponding hydraulic conductivity, $K_{0}$. The pressure head sequence is expected to influence the $K_{0}$ results given the hysteretic nature of the hydraulic conductivity relationship. The objective of this study was to evaluate the influence of the selected pressure head sequence on the hydraulic conductivity of a sandy loam soil measured by a multipotential TI experiment. Twenty experiments were carried out by applying ho values varying between -150 and $+5 \mathrm{~mm}$ (site A). The $h_{0}$ values ranged from -150 to $-10 \mathrm{~mm}$ in another 20 spots (site B). Both wetting and drying values of $K_{0}$ corresponding to $h_{0}=-150,-75$, and $-30 \mathrm{~mm}$ were calculated for each experiment using the measured steady-state flow rates. At both sites, higher $K_{0}$ results were obtained with the descending $h_{0}$ sequence than with the ascending one. The deviations between the two sequences were more noticeable in site A (deviations by a factor ranging from 2.1 to 3.3, depending on $h_{0}$ ) than in site B (deviations by a factor ranging from 1.0 to 2.2), and the values decreased as $h_{0}$ increased. For most of the considered type of site/pressure head combinations, the differences between the $K_{0}$ results were statistically significant $(P=0.05)$. In all cases, the coefficients of variation of the $K_{0}$ data obtained with the two sequences differed at most by a factor of 1.2, suggesting that the applied $h_{0}$ sequence did not affect appreciably the relative variability of the $K_{0}$ results. It was concluded that the dependence of the $K_{0}$ estimates on both the pressure head sequence (ascending or descending) and the highest value of $h_{0}$ used within a descending sequence experiment may be neglected for a rough hydraulic characterization of the selected area. However, both factors should be maintained constant in order to obtain truly comparable $K_{0}$ data from different experiments.
\end{abstract}

Keywords. Hydraulic conductivity, Infiltrometers, Hysteresis.

$\mathrm{F}$ ield measurement of the soil hydraulic conductivity versus pressure head relationship is important for characterizing many aspects of unsaturated soil water flow such as rainfall infiltration and runoff, aquifer recharge, migration of nutrients, pesticides and contaminants through the soil profile, design and monitoring of irrigation and drainage systems (Reynolds, 1993; Hillel, 1998). The hydraulic conductivity of near-saturated soil is critically important since water and solute transport processes occur at the highest rates in these soils. The relation between hydraulic conductivity and pressure head depends upon hysteresis, and is thus different in a wetting than in a drying soil because, at a given pressure head, a drying soil contains more water than a wetting one (Hillel, 1998). The hysteresis effect is in general more pronounced in coarse-textured soils in the high pressure head (low suction) range,

Article was submitted for review in March 2004; approved for publication by the Soil \& Water Division of ASAE in January 2005.

Mention of a product does not constitute endorsement by the University of Palermo or by the authors.

The authors are Vincenzo Bagarello, Associate Professor, Mirko Castellini, PhD Student, and Massimo Iovino, Associate Professor, Dipartimento di Ingegneria e Tecnologie Agro-Forestali, Università degli Studi di Palermo, Italy. Corresponding author: Massimo Iovino, Dipartimento di Ingegneria e Tecnologie Agro-Forestali, Università degli Studi di Palermo, Viale delle Scienze, 90128 Palermo, Italy; phone: +39-091-7028108; fax: +39-091-484035; e-mail: iovinom@unipa.it. where pores may empty at an appreciably lower pressure head than that at which they fill (Hillel, 1998).

The tension infiltrometer (TI) is widely used for measuring the near-saturated hydraulic conductivity in the field (Perroux and White, 1988). Other useful methods for measuring the soil hydraulic conductivity in the field include the instantaneous profile method and the unit gradient drainage method (Reynolds, 1993). Important advantages of these methods are that a large volume of soil is sampled and the hydraulic conductivity can often be measured over a reasonably large range of tensions (Reynolds, 1993). However, these methods require considerable time, large quantities of water, several trained field staff, and considerable equipment (Reynolds, 1993). On the other hand, the TI method is much simpler to use and it gives reliable values of hydraulic conductivity to characterize relatively large areas (Reynolds, 1993; Vandervaere et al., 1998). Therefore, the TI method is potentially preferable to the instantaneous profile method and the unit gradient drainage method, especially for detailed sampling over large areas.

The most commonly applied approaches to determine the soil hydraulic conductivity by the TI method use the Wooding's (1968) analytical solution for steady infiltration from a circular source with the unsaturated hydraulic conductivity given by the Gardner's (1958) exponential model. In particular, a sequence of hydraulic conductivity, $K_{0}$, values corresponding to selected pressure heads, $h_{0}$, can be determined by a steady-state multipotential experiment, 
i.e. by measuring the steady flow rate, $Q_{0}$, for each pressure head imposed on the soil surface (Ankeny et al., 1991; Reynolds and Elrick, 1991; Logsdon and Jaynes, 1993).

For a given set of ordered pressure heads, a multipotential experiment can be carried out by first setting either the highest pressure head [increasing suctions; wet-to-dry (WTD) sequence] or the lowest one [decreasing suctions; dry-to-wet (DTW) sequence]. A WTD sequence is suggested to save time (Ankeny et al., 1991; Ankeny, 1992). By conducting the highest pressure head step first, the wetting front advances as rapidly as possible and the unit gradient assumption is more likely to be valid (Mohanty et al., 1994). On the other hand, a DTW sequence is recommended in order to avoid hysteresis effects due to drainage occurring close to the disc while wetting continues at the infiltration front (Reynolds and Elrick, 1991; Jarvis and Messing, 1995).

When a DTW sequence is applied, the initial soil water content of the sampled soil volume is not uniform starting from the second pressure head onwards, but a wetting process occurs for all pressure heads. Therefore, all $K_{0}$ values are obtained under wetting. When a WTD sequence is applied, a wetting process is established for the first pressure head. Both drainage and wetting processes occur from the second pressure head onwards. Therefore, the measured conductivity derives from a combination of different processes. Due to hysteresis, a WTD sequence should provide higher $K_{0}$ values than a DTW one. Moreover, a higher sensitivity of the $K_{O}$ results to the selected pressure heads is expected with the WTD sequence than with the DTW one. If the DTW sequence is applied, the values of $K_{0}$ corresponding to the lowest pressure heads are independent of the highest pressure head values used for the experiment. Hysteresis theory suggests that, with a WTD sequence, the values of $K_{0}$ corresponding to the lowest pressure heads may vary with the pressure heads established at the beginning of the experiment. Only a few investigations have been carried out to assess the effect of the pressure head sequence on the $K_{0}$ values determined with the TI, suggesting that, in practice, hysteresis is considered to be a minor factor affecting the TI results. Probably, the expected differences between the two sequences are small and practically negligible because soil wetting processes occur with both sequences.

Both appreciable (Logsdon et al., 1993; McKenzie et al., 2001) and practically negligible (Bagarello et al., 2000; Mecke et al., 2000) effects of the sequence used for a multipotential TI experiment on the measured conductivities have been reported. In particular, for two experiments carried out in a silt loam soil, steady infiltration rates obtained in the $-150 \leq h_{0} \leq-30 \mathrm{~mm}$ range with a WTD sequence starting from ponding were 1.05 to 1.93 times higher than the corresponding ones determined by a DTW sequence and the differences between the two approaches increased with the pressure head (Logsdon et al., 1993). For an ascending-descending sequence of $-120,-30$, and $-120 \mathrm{~mm}$ applied on a sandy loam soil, low differences $(<20 \%)$ between the wetting and the drying estimates of $K_{-120}$ (soil hydraulic conductivity corresponding to a pressure head of $-120 \mathrm{~mm}$ ) were detected (Bagarello et al., 2000). No differences between ascending and descending measuring sequences were observed by Mecke et al. (2000) in three soils with a high sand content. Using one-dimensional experiments carried out by a laboratory TI, McKenzie et al. (2001) concluded that the magnitude of the hysteresis effect can be substantial also in soils having a high clay content (differences between $K_{0}$ up to $60 \%$ ). The results summarized above suggest that hysteresis effects may be substantial but they cannot be considered representative of a wide range of conditions for different reasons including the small number of experiments performed (Logsdon et al., 1993), the low number of pressure heads included in the analysis (Bagarello et al., 2000), the seemingly qualitative assessment of the $K_{0}$ sensitivity to the applied sequence (Mecke et al., 2000), and the lack of field support to the laboratory data (McKenzie et al., 2001). Therefore, further investigations have to be carried out.

The objective of this investigation was to examine the influence of the selected sequence of pressure heads on the hydraulic conductivity determined by a multipotential tension infiltrometer experiment in a relatively coarse-textured soil having an appreciable hysteretic behavior. Both the order (ascending or descending) and the values of the pressure heads used for the experiment were allowed to vary in this study.

\section{Materials ANd Methods FIELD SITE}

A $150-\mathrm{m}^{2}$ flat area was used for this study at the Faculty of Agriculture of the Palermo University. The study was conducted on a soil (Typic Rhodoxeralf) having a relatively high sand and gravel content. According to the USDA classification (Gee and Or, 2002) the soil texture of the upper 300-mm layer was sandy loam (Bagarello and Iovino, 2003). The structure of the soil was quite stable, i.e. it varied relatively little with time (Bagarello et al., 2000).

\section{LABORATORY EXPERIMENTS}

A preliminary laboratory investigation was carried out to test the hysteresis of the unsaturated hydraulic properties of the selected soil. To achieve this, four undisturbed soil cores (50 $\mathrm{mm}$ in height $\times 80 \mathrm{~mm}$ in diameter) were collected at the soil surface from the experimental site to evaluate the main wetting and drying water retention functions under a range of pressure head from -30 to $-500 \mathrm{~mm}$, by a hanging water column apparatus (Burke et al., 1986). The apparatus consisted of a sintered porous plate with an air entry value of $-2000 \mathrm{~mm}$ connected to a graduated burette that could move vertically to provide different pressure heads to measure the soil water retention curve. The soil cores were previously air-dried and then progressively wetted on the porous plate. After saturating the core, the pressure head was decreased to the last pressure head value and the final soil water content was determined by oven drying the core. The volume adsorbed from the burette or drained into the burette was recorded and used to calculate the volumetric water content corresponding to each imposed pressure head value. Additional soil water content values for the main drying curve were determined by the pressure plate apparatus (Dane and Hopmans, 2002) in the pressure head range from -1 to $-150 \mathrm{~m}$ on laboratory repacked soil cores. In the high-suction range, measurements of soil moisture retention made with disturbed samples may be expected to reasonably approximate field conditions (Hillel, 1998).

The van Genuchten's (1980) model was assumed to describe the water retention curve: 


$$
S_{e}(h)=\frac{\theta-\theta_{r}}{\theta_{s}-\theta_{r}}=\left[1+|\alpha h| \frac{1}{1-m}\right]^{-m}
$$

where $S_{e}$ is the effective saturation, $\theta\left(\mathrm{L}^{3} \mathrm{~L}^{-3}\right)$ is the volumetric soil water content, $\theta_{s}\left(\mathrm{~L}^{3} \mathrm{~L}^{-3}\right)$ and $\theta_{r}\left(\mathrm{~L}^{3} \mathrm{~L}^{-3}\right)$ are the saturated and the residual water content, respectively, $h$ (L) is the pressure head, and $\alpha\left(\mathrm{L}^{-1}\right)$ and $m$ are empirical parameters. The hysteretic water retention curve was described by assuming different parameter values for the main drying $\left(\alpha_{d}, n_{d}, \theta_{s d}, \theta_{r d}\right)$ and wetting $\left(\alpha_{w}, n_{w}, \theta_{s w}, \theta_{r w}\right)$ curves with the following assumptions (Kool and Parker, 1987):

$$
\begin{gathered}
\theta_{r d}=\theta_{r w}=\theta \\
n_{d}=n_{w}=n
\end{gathered}
$$

The Retention Curve (RETC) code (van Genuchten et al., 1991) was used to fit equation 1 to the laboratory data. According to Kool and Parker (1987), the parameters $\alpha_{d}, n$, $\theta_{s d}$, and $\theta_{r}$ for the main drying curve were first estimated by the soil water content data determined with both the hanging water column and the pressure plate apparatus. Then, the parameters $\alpha_{w}$ and $\theta_{s w}$ for the main wetting curve were estimated by fixing $n$ and $\theta_{r}$ at the values obtained for the main drying curve and using the soil water content values determined by the hanging water column apparatus.

Hysteresis was found to have an appreciable effect on the measured water retention curve (see the Results and Discussion section) and this suggested an hysteretic behavior of the hydraulic conductivity function, too. Therefore, a field investigation with the TI method was carried out.

\section{Choosing the Strategy for Conducting THE FIELD EXPERIMENTS}

Two approaches can be chosen to evaluate the effect of the pressure head sequence on the soil hydraulic conductivity determined in the field with the TI. The first approach consists of applying different sequences (DTW or WTD) at different sites. The second approach consists of applying both sequences at a given site without interruption (dry-to-wet-todry, DTWTD, experiment). Both approaches have advantages and disadvantages.

By the first approach, the $K_{0}\left(\mathrm{~L} \mathrm{~T}^{-1}\right)$ data obtained in different sites (DTW-sequence-sites and WTD-sequencesites) have to be compared. This approach is consistent with the usual practice of applying a single pressure head sequence (DTW or WTD) in the field. Similar initial conditions can be considered for the two types of experiment and this potentially simplifies the comparison. However, the noticeable spatial variability of soil hydraulic conductivity (Warrick, 1998) is an additional factor determining differences among sites (and, hence, between site types) and this can substantially complicate the analysis of the experimental data. The uncertainties due to spatial variability are reduced with the second approach, given that both sequences are applied at a given site. During the ascending portion of a DTWTD experiment, soil wetting processes occur, whereas during the descending portion of the experiment, wetting occurs for the highest pressure head and both drainage and wetting occur for the other pressure heads. Therefore, using an ascending-descending sequence does not introduce a modification of the soil water flow processes as compared to the single-sequence experiments.

A DTWTD experiment is longer than a single-sequence one, but both experiments are relatively short (a few hours long) and start with a high value of the imposed pressure head, independently of the order of the applied pressure heads (in general, $-150 \mathrm{~mm} \leq h_{0}<0$ ). Therefore, appreciable differences in soil structure due to the choice of different TI application procedures (single- or double-sequence) should not be expected.

In general, uniformity of the initial soil water content, $\theta_{i}$ $\left(\mathrm{L}^{3} \mathrm{~L}^{-3}\right)$, at the start of a descending order experiment is more likely to occur for the WTD approach than the DTWTD one given that, with this last approach, $\theta_{i}$ is certainly non-uniform due to previous wetting at lower pressure heads. We did not find in the literature any evaluation of the possible implications of this difference on the TI results. Therefore, the sensitivity of steady flow rate to initial non-uniformity of $\theta_{i}$ was checked by numerical simulation of TI experiments before choosing the experimental approach to be applied in the field. Numerical simulation was carried out by the HYDRUS-2D model (Simunek et al., 1999) using a grid of $50 \times 50$ nodes on a 500- $\times 500$-mm flow domain (Bagarello et al., 2003). The van Genuchten-Mualem model (van Genuchten, 1980) was assumed to describe the hydraulic properties of the soil selected for the field investigation (Iovino, 1998). The radius of the porous disk was set equal to $120 \mathrm{~mm}$. Two experiments (Experiments 1 and 2) were simulated. While Experiment 1 had four pressure heads $\left(h_{0}=\right.$ $-150,-75,-30$, and $-10 \mathrm{~mm}, 1 \mathrm{~h}$ for each pressure head) in ascending order, Experiment 2 was conducted only at a single pressure head $(-10 \mathrm{~mm})$ for a duration of $1 \mathrm{~h}$. The same initial conditions were considered for both experiments (uniform soil water content, $\theta_{i}=0.20 \mathrm{~m}^{3} \mathrm{~m}^{-3}$ ). Steady flow rate at $h_{0}$ $=-10 \mathrm{~mm}$ was higher for Experiment $2\left(2.71 \times 10^{-7} \mathrm{~m}^{3} \mathrm{~s}^{-1}\right)$ than for Experiment $1\left(2.38 \times 10^{-7} \mathrm{~m}^{3} \mathrm{~s}^{-1}\right)$. This result was expected from a qualitative point of view since capillarity effects were reduced at the start of the last pressure head in Experiment 1. The steady flow rate at $h_{0}=-10 \mathrm{~mm}$ determined by Experiment 1 was approximately 12\% lower than the corresponding value obtained with Experiment 2. Therefore, the difference between steady flow rates was low and probably negligible in practice. Results showed that non-uniformity in soil initial water content at the beginning of the descending part in DTWTD experiment had no significant effect on measuring flow rates.

On the basis of this analysis, the potential disadvantages of the DTWTD experiment (additional soil structure alteration, non-uniformity of the initial soil water content) appeared of relatively little importance compared to the advantage of practically removing the confounding effect of spatial variability from the $K_{0}$ results. Therefore, DTWTD experiments were carried out in this investigation.

\section{FIELD EXPERIMENTS}

Tension infiltrometer experiments were conducted at randomly selected locations by using an instrument manufactured by Soil Measurement System (Tucson, Ariz.) consisting of separate water supply and base-plate units. At each location, the soil surface was carefully leveled and smoothed before each experiment and attempts were made to prevent infiltration surface smearing. A level was used to assure that 
the disc and the reservoir base were always at the same height (zero relative distance, fig. 1a), so that the head between the bubbling outlet at the bottom of the water supply tube and the disc membrane was constant. A retaining ring with a radius of $120 \mathrm{~mm}$ (fig. 1b) and a nylon guard cloth having an air entry value of $-160 \mathrm{~mm}$ were placed on the soil surface. To avoid formation of artificial pores due to ineffective contact with the soil surface, the nylon cloth guard was previously wetted and carefully spread on the soil surface. A contact layer having a thickness of $10 \mathrm{~mm}$ was prepared by using dry Spheriglass no. 2227 glass spheres (Potter Ballotini GmbH, Kirchheimbolanden, Germany). Pressure heads imposed at the infiltrometer membrane were corrected to account for the thickness of the contact material layer (Reynolds and Zebchuck, 1996).

A total of $40 \mathrm{TI}$ experiments were conducted in the summer months of 2000 and 2002. Two DTWTD pressure head sequences differing by the highest value of $h_{0}$ were considered to also evaluate the effect of the highest pressure head imposed with the instrument on the $K_{0}$ data obtained within a descending pressure head sequence. In particular, the following $h_{0}$ values were imposed in sequence without interruption in 20 sites (sites A): $-150,-75,-30,+5,-30,-75$, $-150 \mathrm{~mm}$. The positive pressure head $(+5 \mathrm{~mm})$ at the soil surface resulted from the sum of the pressure head established on the infiltrometer membrane $(-5 \mathrm{~mm})$ and the contact material layer thickness $(10 \mathrm{~mm})$ (Reynolds and Zebchuck, 1996). A small positive pressure head was used instead of $h_{0}$ $=0$ to be reasonably sure that field-saturated conditions were established with the highest pressure head of the sequence (Logsdon et al., 1993). The following $h_{0}$ values were imposed in the other 20 spots (site B): $-150,-75,-30,-10,-30$, -75 , and $-150 \mathrm{~mm}$.

For most experiments, two reservoirs were connected to a single porous disc to facilitate refilling procedures (fig. 1c). The mean duration of the experiment for a given pressure head varied between a minimum of $20.1 \mathrm{~min}$ for $h_{0}=+5 \mathrm{~mm}$ and a maximum of $60 \mathrm{~min}$ for $h_{0}=-150 \mathrm{~mm}$ (wetting sequence). A wetted zone appeared at the soil surface during the experiment (fig. 1d). Water level readings were collected visually at 0.25 - to 5-min intervals. Apparent steady state infiltration rates were calculated from the slope of the linear portion of the cumulative infiltration versus time plot (Bagarello et al., 1999). Soil hydraulic conductivity, $K_{0}$, corresponding to each imposed pressure head, $h_{0}$, was calculated by using Wooding's (1968) analysis for unconfined steady-state infiltration from a disc into homogeneous, isotropic, uniformly unsaturated soil. In particular, the method of Ankeny et al. (1991) was applied to determine the values of $K_{0}$ corresponding to pressure heads of $-150,-75$, and $-30 \mathrm{~mm}$. Two estimates of $K_{0}$ were obtained for each intermediate $h_{0}$ value of the applied sequence. In this case the best estimate of $K_{0}$ was obtained as the arithmetic average of the available estimates (Ankeny et al., 1991). For the experiments carried out in site $\mathrm{A}$, a pressure head equal to zero was used in the calculation of the $K_{0}$ value corresponding to a pressure head of $-30 \mathrm{~mm}\left(K_{-30}\right)$ instead of the real value $\left(h_{0}=+5 \mathrm{~mm}\right)$. This procedure of analysis of the data has also been applied by other authors since it greatly simplifies the calculations and it does not affect appreciably the $K_{0}$ results (Reynolds et al., 1995). For the data used in this investigation, the application of the One-Ponding-Depth

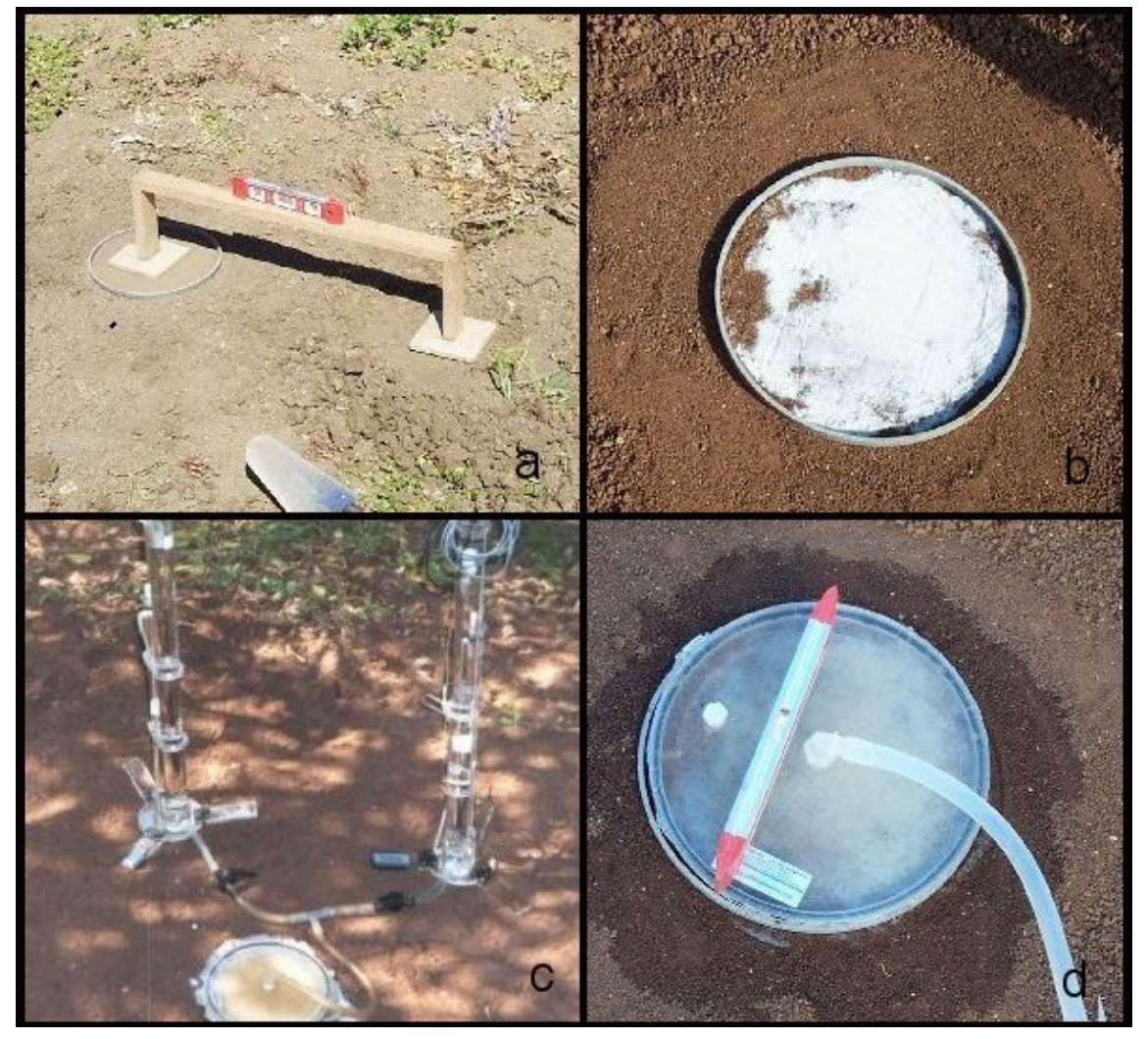

Figure 1. Field tension infiltrometer procedure: (a) leveling procedure; (b) retaining ring details; (c) connection of two reservoirs to a single porous disc; (d) wetted zone at the soil surface during the experiment. 
approach (Reynolds and Elrick, 1990) confirmed that using $h_{0}=0$ instead of $h_{0}=+5 \mathrm{~mm}$ had a negligible effect on the field-saturated hydraulic conductivity estimates (differences between $K_{0}$ results $\left.\leq 6 \%\right)$. Averaging the available estimates of $K_{-30}$ (one obtained by considering $h_{0}=-75$ and $-30 \mathrm{~mm}$ and the other deduced by using $h_{0}=-30 \mathrm{~mm}$ and 0 ) contributed to further reduce the expected low error in the $K_{-30}$ predictions.

\section{Statistical Analysis}

The statistical frequency distributions for the $K_{0}$ data obtained in the field were log-normal, which is common for this soil property (Warrick, 1998). Therefore, all statistical tests of the $K_{0}$ results were carried out using the natural logs of the data. Also, the means $\left(\bar{K}_{0}\right)$ and the associated coefficients of variation $(C V)$ were calculated using the appropriate "log-normal" equations (Lee et al., 1985). In the data statistical analysis, a probability level $P=0.05$ was assumed.

\section{Results AND Discussion}

\section{LABORATORY EXPERIMENTS}

For each soil core, the main wetting and drying water retention curves determined in the pressure head range -500 $\leq h \leq-30 \mathrm{~mm}$ differed appreciably (fig. 2). In particular, the mean values of the soil water content measured during drying $\left(\theta_{d}\right)$ were 1.16 to 1.22 times higher than the corresponding values obtained by wetting $\left(\theta_{w}\right)$, depending on the applied pressure head. Application of a two-tailed, paired t-test showed that, for a given pressure head, the difference between the two data sets was statistically significant. The following parameters of the hysteretic water retention curve were obtained by fitting equation 1 to the mean $\theta_{w}$ and $\theta_{d}$ data obtained for each pressure head: $\alpha_{w}=0.1397 \mathrm{~cm}^{-1} ; \alpha_{d}=$ $0.0830 \mathrm{~cm}^{-1} ; n=1.2819 ; \theta_{s w}=0.4561 \mathrm{~m}^{3} \mathrm{~m}^{-3} ; \theta_{s d}=0.5150$ $\mathrm{m}^{3} \mathrm{~m}^{-3} ; \theta_{r}=0.09 \mathrm{~m}^{3} \mathrm{~m}^{-3}$. The measured boundary

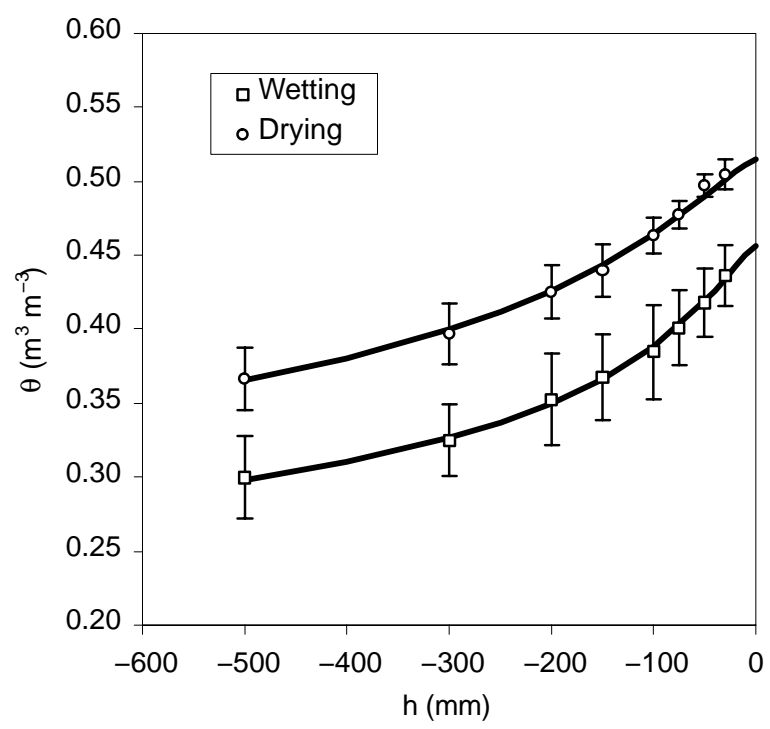

Figure 2. Measured volumetric soil water content $(\theta)$ vs. pressure head (h) values for the main wetting (open squares) and drying (open circles) water retention curves. The error bars indicate \pm 1 standard deviation. Fitted van Genuchten's (1980) relationships, equation 1, are also plotted (solid lines). hysteretic loop was not closed at saturation and the difference between the estimated values of $\theta_{s d}$ and $\theta_{s w}$ was remarkable $\left(0.06 \mathrm{~m}^{3} \mathrm{~m}^{-3}\right)$. The theoretically invoked assumption that the hysteretic retention curve should exhibit closure at $h=0$ (Haverkamp et al., 2002) has often been contradicted in field soils due to entrapped air (Kaluarachchi and Parker, 1987). Differences between $\theta_{s w}$ and $\theta_{s d}$ up to 0.086 were reported for an undisturbed loam soil by Kool and Parker (1987). In our case, air was perhaps entrapped in the soil cores during wetting and it was removed as the cores were completely saturated before starting with the main drying curve determination. The $\alpha_{w} / \alpha_{d}$ ratio was equal to 1.7 . This value was close to the ratio suggested by Kool and Parker (1987) to estimate the hysteretic water retention function parameters when specific data are not available $\left(\alpha_{w} / \alpha_{d}=2\right)$.

In conclusion, the soil had a clearly hysteretic behavior. Therefore, an appreciable sensitivity of the hydraulic conductivity to the physical process occurring in the soil (wetting or drying) was expected for this soil (Hillel, 1998).

\section{FIELD EXPERIMENTS}

For both sites (A and B), higher values of $K_{0}$ were generally obtained within the drying sequence (hydraulic conductivity denoted by the symbol $K_{0, d}$ ) than within the wetting one $\left(K_{0, w}\right)$ (fig. 3). In particular, for the spots where ponding conditions were established during the experiment (site A), the mean values of $K_{0, d}$ corresponding to $h_{0}=-150$, -75 , and $-30 \mathrm{~mm}$ were $3.28,2.89$, and 2.05 times higher than the corresponding mean values of $K_{0, w}$ (table 1). For the spots where unsaturated conditions were maintained for all the experiment (site B), the mean values of $K_{0, d}$ corresponding to $h_{0}=-150,-75$, and $-30 \mathrm{~mm}$ were higher than the corresponding mean values of $K_{0, w}$ by a factor of $2.21,1.80$, and 1.03, respectively. According to a two-tailed, paired t-test, the differences between $\bar{K}{ }_{0, d}$ and $\bar{K}_{0, w}$ were statistically significant for the imposed pressure heads of -150 and $-75 \mathrm{~mm}$ at both site types and for $h_{0}=-30 \mathrm{~mm}$ at site A only (table 1). Within the considered type of site/pressure head combinations, the coefficients of variation of the $K_{0, d}$ and $K_{0, w}$ data differed at the most by a factor of 1.20 (table 1 ).

Therefore, the order of the pressure heads imposed on the soil surface for a TI experiment affected the measured hydraulic conductivity. In particular, higher results were obtained with a descending sequence of $h_{0}$ values than with an ascending one, as it was expected in a hysteretic soil (Hillel, 1998). Independently of the highest pressure head used for the experiment, the discrepancies between the two sequences decreased as the imposed pressure head increased. Higher discrepancies between $K_{0, d}$ and $K_{0, w}$ were detected when ponding conditions were established at a phase of the experiment than when unsaturated conditions were maintained for the whole experiment. The applied sequence (increasing or decreasing) did not substantially affect the relative variability of the individual $K_{0}$ data. According to these results, the low differences between the wetting and the drying estimates of the hydraulic conductivity detected by Bagarello et al. (2000) for the same soil used in this investigation were probably due to the fact that the maximum value of $h_{0}$ applied on the soil surface was relatively low (-30 $\mathrm{mm})$. 

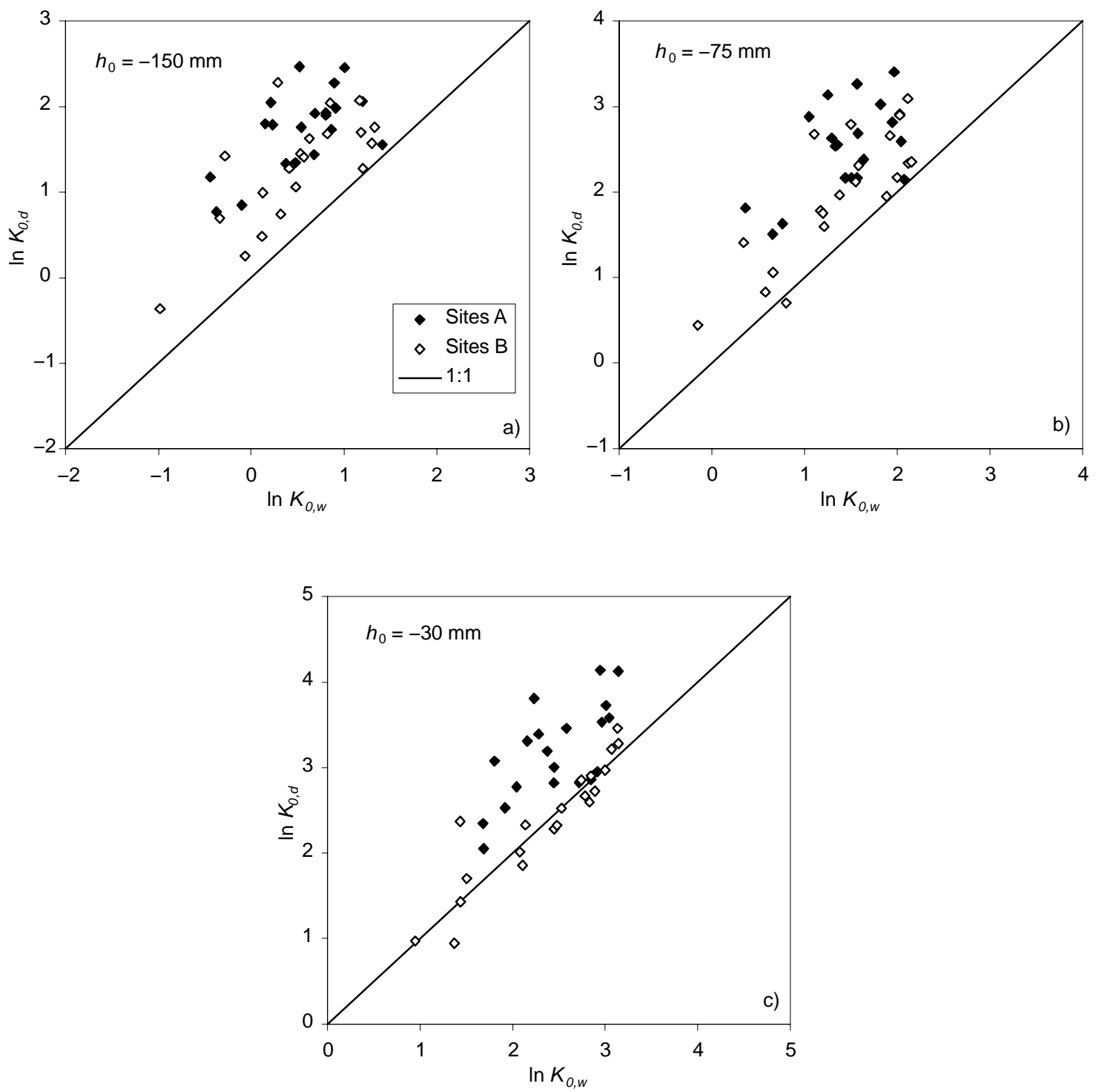

Figure 3. Comparison of hydraulic conductivity estimates obtained, at different pressure head values $\left(h_{0}\right)$ within the wetting sequence $\left(K_{0, w}\right)$ and the drying sequence $\left(K_{0, \mathrm{~d}}\right)$ in site A (solid diamonds) and in site B (open diamonds). a) $\left.\left.h_{0}=-150 \mathrm{~mm} ; \mathrm{b}\right) h_{0}=-75 \mathrm{~mm} ; \mathrm{c}\right) h_{0}=-30 \mathrm{~mm}$.

The mean values of $K_{0}$ obtained within the wetting sequence in site $\mathrm{A}$ were between 1.06 and 1.12 times higher than the corresponding values obtained in site B, depending on the imposed pressure head, and the differences between the two data sets were not statistically significant according to a two-tailed t-test (table 1). On the other hand, site A produced values of $\bar{K}_{0, d}$ that were higher than the site B by a factor ranging between 1.58 and 2.23 . The discrepancies between the two sets of data were statistically significant according to a two-tailed t-test and they increased with the applied pressure head (table 1). Therefore, the starting point

Table 1. Geometric mean $\left(\bar{K}_{0}\right)$ and associated coefficient of variation $(\mathrm{CV})$ of the hydraulic conductivity estimates obtained at different pressure heads $\left(h_{0}\right)$ during the wetting $\left(K_{0, w}\right)$ and the drying $\left(K_{0, d}\right)$ sequence in sites $A$ and $B$.

\begin{tabular}{|c|c|c|c|c|c|c|c|}
\hline \multirow[b]{2}{*}{ Site } & & \multicolumn{2}{|c|}{$h_{0}=-150(\mathrm{~mm})$} & \multicolumn{2}{|c|}{$h_{0}=-75(\mathrm{~mm})$} & \multicolumn{2}{|c|}{$h_{0}=-30(\mathrm{~mm})$} \\
\hline & & $\mathrm{K}_{0, \mathrm{w}}$ & $\mathrm{K}_{0, \mathrm{~d}}$ & $\mathrm{~K}_{0, \mathrm{w}}$ & $\mathrm{K}_{0, \mathrm{~d}}$ & $\mathrm{~K}_{0, \mathrm{w}}$ & $\mathrm{K}_{0, \mathrm{~d}}$ \\
\hline \multirow[t]{2}{*}{ A } & $\bar{K}_{0}\left(\mathrm{mmh}^{-1}\right)$ & $1.720 \mathrm{a}^{[\mathrm{a}]} \mathrm{A}^{[\mathrm{b}]}$ & $5.640 \mathrm{bA}$ & 4.303aA & $12.435 \mathrm{bA}$ & $11.704 \mathrm{aA}$ & $23.941 \mathrm{bA}$ \\
\hline & CV (\%) & 52.0 & 49.6 & 50.6 & 56.4 & 50.5 & 60.6 \\
\hline \multirow[t]{2}{*}{ B } & $\bar{K}_{0}\left(\mathrm{mmh}^{-1}\right)$ & $1.618 \mathrm{aA}$ & $3.570 \mathrm{bB}$ & $3.883 \mathrm{aA}$ & $6.992 \mathrm{bB}$ & $10.425 \mathrm{aA}$ & $10.714 \mathrm{aB}$ \\
\hline & CV (\%) & 67.8 & 73.4 & 73.4 & 87.7 & 77.0 & 81.2 \\
\hline
\end{tabular}

[a] For given $h_{0}$, values in a row followed by the same lower case letter are not statistically different at the probability level $P=0.05$ according to a two-tailed paired t-test.

[b] For given variable, values in a column followed by the same capital letter are not statistically different at the probability level $P=0.05$ according to a two-tailed $\mathrm{t}$-test. 
of the descending sequence had a noticeable effect on the measured conductivity. In particular, higher $K_{0}$ results were obtained as the highest pressure head of the sequence increased. For a given variable $\left(K_{0, w}\right.$ or $\left.K_{0, d}\right)$ and an imposed pressure head, the $C V$ of the individual measurements obtained in site B was between 1.30 and 1.56 times higher than the corresponding $C V$ obtained in site A (table 1).

In all cases, linear regression between $\ln \left(K_{0, d}\right)$ and $\ln \left(K_{0, w}\right)$ was statistically significant, with coefficients of determinations, $r^{2}$, ranging between 0.330 and 0.846 (table 2). In general, the values of the intercept decreased and both the slopes of the regression line and the associated coefficients of determination increased as the imposed pressure head increased from -150 to $-30 \mathrm{~mm}$ (table 2). In most cases, the intercept was significantly different from zero and the slope was not different from unity (table 2). The increase of the coefficient of determination of the regression between $K_{0, d}$ and $K_{0, w}$ with $h_{0}$, which was observed in both types of site, could be indicative of a relatively poor quality of the $K_{0}$ results corresponding to the lowest values of $h_{0}$. In particular, $K_{O}$ data characterized by a low representativeness and reproducibility may be obtained for low pressure heads because the hydraulic contact between the infiltrometer membrane and the infiltration surface can be particularly precarious in this case (Close et al., 1998). However, the increase of $r^{2}$ (table 2) was associated with a decrease of the differences between $\bar{K}_{0, d}$ and $\bar{K}_{0, w}$ (table 1). Moreover, a lower correlation between the $K_{0, d}$ and $K_{0, w}$ data was obtained in site A than in B. Therefore, a more likely interpretation was that the observed trend between $r^{2}$ and $h_{0}$ was a consequence of the hysteretic behavior of the tested soil.

A relatively low difference between $\bar{K}_{0, d}$ and $\bar{K}_{0, w}$ suggests that the hysteresis phenomena have a relatively small effect on the conductivity measurements. In this case, the factors determining the soil's ability to transmit water (conductive portion of the soil cross sectional area, tortuosity) should not vary appreciably with the sequence of pressure heads used for the experiment. As a result, a relatively high correlation between $K_{0, d}$ and $K_{0, w}$ is expected. On the other hand, appreciable hysteresis phenomena are responsible for large differences between $\bar{K}_{0, d}$ and $\bar{K}_{0, w}$. In this case, the factors determining the soil's ability to transmit water vary with the considered sequence and values of $K_{0}$ obtained with different sequences may be poorly correlated.

Table 2. Parameters of the linear regression between the In-transformed $K_{0}$ data obtained with the drying $\left(K_{0, d}\right.$, dependent variable) and wetting $\left(K_{0, w}\right.$, independent variable) sequences.

\begin{tabular}{ccccc}
\hline Site & $\begin{array}{c}\text { Pressure Head } \\
(\mathrm{mm})\end{array}$ & Intercept & Slope & $\begin{array}{c}\text { Coefficient of } \\
\text { Determination }\end{array}$ \\
\hline \multirow{3}{*}{$\mathrm{A}$} & -150 & $1.409^{[\mathrm{a}]}$ & $0.592^{[\mathrm{c}]}$ & $0.381^{[\mathrm{e}]}$ \\
& -75 & $1.597^{[\mathrm{a}]}$ & $0.633^{[\mathrm{d}]}$ & $0.330^{[\mathrm{e}]}$ \\
& -30 & $1.219^{[\mathrm{a}]}$ & $0.795^{[\mathrm{d}]}$ & $0.460^{[\mathrm{e}]}$ \\
\hline \multirow{3}{*}{$\mathrm{B}$} & -150 & $0.898^{[\mathrm{a}]}$ & $0.778^{[\mathrm{d}]}$ & $0.531^{[\mathrm{e}]}$ \\
& -75 & $0.648^{[\mathrm{a}]}$ & $0.956^{[\mathrm{d}]}$ & $0.691^{[\mathrm{e}]}$ \\
& -30 & $0.122^{[\mathrm{b}]}$ & $0.959^{[\mathrm{d}]}$ & $0.846^{[\mathrm{e}]}$ \\
\hline
\end{tabular}

[a] Significantly different from zero $(P=0.05)$.

[b] Not significantly different from zero $(P=0.05)$.

[c] Significantly different from one $(P=0.05)$.

[d] Not significantly different from one $(P=0.05)$.

[e] Significantly greater than zero $(P=0.05)$.
Larger pores are activated as the maximum pressure head imposed within a sequence increases. Consequently, the probability that factors determining the soil's ability to transmit water differ between the wetting and the drying sequence increases with the highest value of $h_{0}$ considered. In other words, an increase of the maximum pressure head imposed on the soil surface is expected to yield a larger difference and a lower correlation between the $K_{0, d}$ and $K_{0, w}$ data sets corresponding to a given pressure head.

In general, the mean values of $K_{0}$ obtained by varying the pressure head order and the highest pressure head imposed on the soil surface differed by a factor ranging approximately between 1.0 and 3.0. Given that the investigation was conducted in a relatively coarse-textured soil, this level of discrepancies should be reasonably indicative to some extent of a maximum sensitivity of the $K_{0}$ estimates to the TI application procedure. The DTW part of the DTWTD experiment suggested that the two sites (A and B) had a similar ability to transmit water but this ability was lower than the one detected by the WTD part of the DTWTD experiment. By this last approach (descending sequence), a larger ability to transmit water was detected for site A than for site $\mathrm{B}$ and the conclusion was that the two sites did not have similar conductivity characteristics.

It can be considered acceptable for many practical purposes to have an uncertainty in the soil hydraulic conductivity estimates (at least, the saturated ones) by a factor of two or three (Elrick and Reynolds, 1992; Reynolds and Zebchuk, 1996; Elrick et al., 2002). Therefore, the discrepancies observed in this investigation between different application procedures of a multipotential TI experiment could be considered negligible, suggesting that both the pressure head sequence and the highest value of $h_{0}$ were minor factors affecting the measured hydraulic conductivity of the study area. However, the investigation also showed that the choice of the application procedure of the TI method had practical implications on the detection of the relative conductivity characteristics of the two sites.

According to these results, it is suggested that a rough hydraulic characterization of the study area does not need to take into account the sensitivity of the $K_{0}$ measurements to both the pressure head sequence and the highest value of $h_{0}$ used for a WTD experiment. However, these two factors have to be considered to obtain truly comparable data from different experiments and, therefore, to reduce uncertainties in comparative studies.

\section{Summary AND CONCluSions}

Both an increasing (DTW) and a decreasing (WTD) sequence of pressure heads can be used for a multipotential tension infiltrometer (TI) experiment. Soil wetting processes occur with a DTW sequence. Both drainage and wetting processes occur with a WTD sequence. Due to soil's hysteresis, the sequence of pressure heads can influence the measured soil hydraulic conductivity.

The focus of this study was the dependence of the soil hydraulic conductivity measurements on the pressure heads imposed on the soil surface with a multipotential TI experiment in a sandy loam soil. This soil was selected based on a preliminary laboratory result that highlighted the hysteretic behaviour. In particular, the main drying volumet- 
ric soil water content was 1.16 to 1.22 times higher than the main wetting one, depending on the pressure head, for pressure heads ranging from -500 to $-30 \mathrm{~mm}$.

Forty dry-to-wet-to-dry experiments were carried out in randomly selected sites. The imposed pressure heads, $h_{0}$, varied between $-150 \mathrm{~mm}$ and $+5 \mathrm{~mm}$ in 20 spots (site A). The $h_{0}$ values ranged from -150 to $-10 \mathrm{~mm}$ in another 20 spots (site B). Apparent steady-state infiltration rates were used to determine both the wetting and the drying soil hydraulic conductivity, $K_{0}$, corresponding to $h_{0}$ values of $-150,-75$, and $-30 \mathrm{~mm}$.

In both sites, higher values of $K_{0}$ were obtained in descending order of $h_{0}$ values than the ascending one, as it was expected in a hysteretic soil.

The discrepancies between the two sequences decreased as the imposed pressure head increased. In particular, the mean values of $K_{0}$ obtained in site A with the drying sequence were 2.1 to 3.3 times higher than the corresponding results obtained under wetting conditions. For site B, these discrepancies were in the range of 1.0 to 2.2. Within the considered type of site/pressure head combinations, the coefficients of variation of the hydraulic conductivity data obtained with the two sequences differed at the most by a factor of 1.2, suggesting that the applied sequence did not substantially affect the relative variability of the individual $K_{0}$ measurements. Data obtained by an ascending pressure head sequence suggested that the two groups of sites had similar conductivity characteristics (mean values of hydraulic conductivity differing by a factor of approximately 1.1). However, site A was found to have a larger mean conductivity than site B (by a factor ranging between 1.6 and 2.2, depending on $h_{0}$ ) when data obtained by a descending sequence were compared.

McKenzie et al. (2001) concluded that significant errors of interpretation may occur if measurements made on desorption and adsorption curves are considered comparable. This conclusion was confirmed and extended in this field investigation since an appreciable effect of the highest pressure head of a WTD sequence on the measured conductivity was also detected.

In practice, the sensitivity of the $K_{0}$ measurements to both the pressure head sequence and the highest value of $h_{0}$ used for a WTD experiment may be considered negligible in the selected area if the order of magnitude of the soil hydraulic conductivity has to be evaluated. However, these two factors have to be considered to obtain truly comparable data from different experiments and, therefore, to reduce uncertainties in comparative studies.

An implication of this investigation is that the multipotential TI experiment may be considered as a versatile method for obtaining data representative of specific hydrological processes. For example, a DTW sequence may be applied to deduce hydraulic conductivity data suitable for interpreting or simulating rain infiltration processes. A WTD sequence starting from $h_{0}=0$ may be used if the process of interest is drainage of an initially saturated soil. Due to the physical characteristics of the selected soil, the results of this investigation might be indicative of the maximum sensitivity of the $K_{0}$ estimates to the TI application procedure. However, this last conclusion should be supported by additional experimental investigations.

\section{ACKNOWLEDGEMENTS}

This study was supported by grants of Università degli Studi di Palermo (Italy). V. Bagarello and M. Iovino set up the research, M. Castellini conducted most of experimental work. All authors analysed the results and participated in writing the article. M. Castellini developed this research for his PhD activity.

\section{REFERENCES}

Ankeny, M. D. 1992. Methods and theory for unconfined infiltration measurements. In Advances in Measurements of Soil Properties: Bringing Theory into Practice, eds. G. C. Topp et al., 123-141. Madison, Wis.: Soil Sci. Soc. Am.

Ankeny, M. D., M. Ahmed, T. C. Kaspar, and R. Horton. 1991. Simple field method for determining unsaturated hydraulic conductivity. Soil Sci. Soc. Am. J. 55(2): 467-470.

Bagarello, V., and M. Iovino. 2003. Field testing parameter sensitivity of the two-term infiltration equation using differentiated linearization. Vadose Zone J. 2(3): 358-367.

Bagarello, V., M. Iovino, and W. D. Reynolds. 1999. Measuring hydraulic conductivity in a cracking clay soil using the Guelph permeameter. Transactions of the ASAE 42(4): 957-964.

Bagarello V., M. Iovino, and G. Tusa. 2000. Factors affecting measurement of the near saturated soil hydraulic conductivity. Soil Sci. Soc. Am. J. 64(4): 1203-1210.

Bagarello, V., M. Iovino, and D. Ventrella. 2003. Testing the inverse method with numerically generated tension infiltrometer data for a fine-textured soil. In Proc. of XXX CIOSTA-CIGR V Congress, 1218-1227.

Burke, W., D. Gabriels, and J. Bouma. 1986. Soil Structure Assessment. Rotterdam, The Netherlands: Balkema.

Close, K. R., G. Frasier, G. H. Dunn, and J. C. Loftis. 1998. Tension infiltrometer contact interface evaluation by use of a potassium iodide tracer. Transactions of the ASAE 41(4): 995-1004.

Dane, J. H., and J. W. Hopmans. 2002. Water retention and storage: laboratory. In Methods of Soil Analysis, Physical Methods, eds. J. H. Dane and G. C. Topp, Part 4, 3rd ed., 688-692. Madison, Wis.: Soil Sci. Soc. Am.

Elrick, D. E., and W. D. Reynolds. 1992. Infiltration from constant-head well permeameters and infiltrometers. In Advances in Measurements of Soil Properties: Bringing Theory into Practice, eds. G. C. Topp et al., 1-24. Madison, Wis.: Soil Sci. Soc. Am.

Elrick, D. E., R. Angulo-Jaramillo, D. J. Fallow, W. D. Reynolds, and G. W. Parkin. 2002. Analysis of infiltration under constant head and falling head conditions. In Environmental Mechanics: Water, Mass and Energy Transfer in the Biosphere, eds. P. A. C. Raats et al., 47-53. Washington, D.C.: AGU.

Gardner, W. R. 1958. Some steady-state solutions of the unsatured moisture flow equation with application to evaporation from a water table. Soil Sci. 85: 228-232.

Gee, G. W., and D. Or. 2002. Particle-size analysis. In Methods of Soil Analysis, Physical Methods, eds. J. H. Dane and G. C. Topp, Part 4, 3rd ed., 255-293. Madison, Wis.: Soil Sci. Soc. Am.

Haverkamp, R., P. Reggiani, P. J. Ross, and J. Y. Parlange. 2002. Soil water hysteresis prediction model based on theory and geometric scaling. In Environmental Mechanics: Water, Mass and Energy Transfer in the Biosphere, eds. P.A.C. Raats et al. Washington, D.C.: AGU

Hillel, D. 1998. Environmental Soil Physics. San Diego, Calif.: Academic Press.

Iovino, M. 1998. Applicazione della tecnica "multistep outflow" per la determinazione delle proprietà idrauliche del terreno col metodo inverso. Rivista di Irrigazione e Drenaggio 45: 25-30 (in Italian with English abstract) 
Jarvis, N. J., and I. Messing. 1995. Near-saturated hydraulic conductivity in soils of contrasting texture measured by tension infiltrometers. Soil Sci. Soc. Am. J. 59: 27-34

Kaluarachchi, J. J., and J. C. Parker. 1987. Effects of hysteresis with air entrapment on water flow in the unsaturated zone. Water Resour. Res. 23(10): 1967-1976.

Kool, J. B., and J. C. Parker 1987. Development and evaluation of closed-form expressions for hysteretic soil hydraulic properties. Water Resour. Res. 23(1): 105-114.

Lee, D. M., W. D. Reynolds, D. E. Elrick, and B. E. Clothier. 1985. A comparison of three field methods for measuring saturated hydraulic conductivity. Can. J. Soil Sci. 65: 563-573.

Logsdon, S. D., and D. B. Jaynes. 1993. Methodology for determining hydraulic conductivity with tension infiltrometers. Soil Sci. Soc. Am. J. 57(6): 1426-1431.

Logsdon, S. D., E. L. McCoy, R. R. Allmaras, and D. R. Linden. 1993. Macropore characterization by indirect methods. Soil Sci. 155(5): 316-324.

McKenzie, N. J., H. P. Cresswell, H. Rath, and D. Jacquier 2001. Measurement of unsatured hydraulic conductivity using tension and drip infiltrometers. Aust. J. Soil Res. 39(4): 823-836.

Mecke, M., C. J. Westman, and H. Ilvesniemi. 2000. Prediction of near-saturated hydraulic conductivity in three podzolic boreal forest soils. Soil Sci. Soc. Am. J. 64(2): 485-492.

Mohanty, B. P., M. D. Ankeny, R. Horton, and R. S. Kanwar 1994. Spatial analysis of hydraulic conductivity measured using disc infiltrometers. Water Resour. Res. 30(9): 2489-2498.

Perroux, K. M., and I. White 1988. Designs for disc permeameters. Soil Sci. Soc. Am. J. 52(5): 1205-1215.

Reynolds, W. D. 1993. Unsatured hydraulic conductivity: field measurement. In Soil Sampling and Methods of Analysis, ed. M. R. Carter, 633-644. Boca Raton, Fla.: Lewis Publishers, Canadian Society of Soil Science.

Reynolds, W. D., and D. E. Elrick. 1990. Ponded infiltration from a single ring. Part 1. Analysis of steady flow. Soil Sci. Soc. Am. J. 54(5): 1233-1241.
Reynolds, W. D., and D. E. Elrick 1991. Determination of hydraulic conductivity using tension infiltrometer. Soil Sci. Soc. Am. J. 55(3): 633-639.

Reynolds, W. D., and W. D. Zebchuk 1996. Use of contact material in tension infiltrometer measurements. Soil Technology 9: 141-159.

Reynolds, W. D., E. G . Gregorich, and W. E. Curnoe. 1995. Characterisation of water transmission properties in tilled and untilled soils using tension infiltrometers. Soil \& Tillage Research 33(2): 117-131.

Reynolds, W. D., D. E. Elrick, E. G. Young, H. W .G. Booltink, and J. Bouma. 2002. Saturated and field-saturated water flow parameters: water transmission parameters: Laboratory methods. In Methods of Soil Analysis, Physical Methods, eds. J. H. Dane, and G. C. Topp, Part 4, 3rd ed., 802-817. Madison, Wis.: Soil Sci. Soc. Am.

Simunek, J., M. Sejna, and M. Th. van Genuchten. 1999. HYDRUS-2D. Simulating water flow and solute transport in two-dimensional variably saturated media. Version 2.0. IGWMC-TPS53C. International Ground Water Modeling Center, Colorado School of Mines. Golden, Colo.

Vandervaere, J. P., M. Vauclin, R. Haverkamp, C. Peugeot, J. L. Thony, and M. Gilfedder. 1998. Prediction of crust-induced surface runoff with disc infiltrometer data. Soil Sci. 163(1): 9-21

van Genuchten, M. T. 1980. A closed form equation for predicting the hydraulic conductivity of unsaturated soils. Soil Sci. Soc. Am. J. 44: 892-898.

van Genuchten, M. Th., F. J. Leij, and S. R. Yates. 1991. The RETC code for quantifying the hydraulic functions of unsaturated soils. Riverside, Calif.: U.S. Salinity Laboratory.

Warrick, A. W. 1998. Spatial variability. In Environmental Soil Physics, ed. D. Hillel, 655-675. San Diego, Calif.: Academic Press.

Wooding, R. A. 1968. Steady infiltration from a shallow circular pond. Water Resour. Res. 4(6): 1259-1273. 
View publication stats 